\title{
Chapter 14 \\ Dose Estimation of External and Internal Exposure in Japanese Macaques After the Fukushima Nuclear Power Plant Accident
}

\author{
Satoru Endo, Kenichi Ishii, Masatoshi Suzuki, Tsuyoshi Kajimoto, \\ Kenichi Tanaka, and Manabu Fukumoto
}

\begin{abstract}
Cumulative dose of external and internal exposures following the Fukushima Daiichi Nuclear Power Plant (FNPP) accident was estimated for Japanese macaques (Macaca fuscata) around FNPP. Conversion factors for Japanese macaques modeled as ellipsoids were estimated for external exposure from contaminated ground and internal exposure uniformly distributed in the body. Conversion factors for seven radionuclides, namely, tellurium-129 $\left({ }^{129} \mathrm{Te}\right),{ }^{129 \mathrm{~m}} \mathrm{Te}$, iodine-131 $\left({ }^{131} \mathrm{I}\right),{ }^{132} \mathrm{Te},{ }^{132} \mathrm{I}$, cesium-134 $\left({ }^{134} \mathrm{Cs}\right)$ and ${ }^{137} \mathrm{Cs}$ were calculated using the PHITS code. The estimated factors for the seven radionuclides were consistent with those in ICRP Publication 108, using an effective radius for comparison. The external, internal and total exposures for 13 macaques in Namie Town were estimated by applying the calculated factors. The estimated cumulative exposures for the periods from the accident occurred to the sampling date, ranged from 0.26 to $1.6 \mathrm{~Gy}$. The average exposure was $0.64 \mathrm{~Gy}$ in averaged over the 11 sampled macaques except for the 2 macaques which might be born after the FNPP accident.
\end{abstract}

Keyword Fukushima Daiichi Nuclear Power Plant accident · Dose rate conversion factor $\cdot$ External exposure $\cdot$ Internal exposure $\cdot$ Japanese macaques

\footnotetext{
S. Endo $(\varangle) \cdot$ K. Ishii $\cdot$ T. Kajimoto $\cdot$ K. Tanaka

Quantum Energy Applications, Graduate School of Engineering, Hiroshima University,

Higashi-Hiroshima, Hiroshima, Japan

e-mail: endos@hiroshima-u.ac.jp

M. Suzuki

Institute for Disaster Reconstruction and Regeneration Research, Tohoku University,

Sendai, Japan

M. Fukumoto

Institute of Development, Aging and Cancer, Tohoku University, Sendai, Japan

School of Medicine, Tokyo Medical University, Tokyo, Japan
} 


\subsection{Introduction}

The nuclear accident at the Fukushima Daiichi Nuclear Power Plant (FNPP) was triggered by an enormous earthquake and associated tsunami (the Great East Japan Earthquake) on March 11, 2011. A large quantity of radioactive nuclides were released, resulting in the severe contamination of a wide area of the southern Tohoku region to the northern Kanto region. The main depositions occurred on March 15 and March 20-21, 2011 [1, 2].

Since the accident, many studies have examined the effect of radiation on animals, insects and plants [3-8]. However, cumulative exposure in animals is quite difficult to estimate because it is challenging to account for habitat and behavioral properties. Estimates of exposure could be improved using a contamination map combined with habitat information. Dose rate and its temporal changes can be estimated for target animals in an area from the contamination map.

The National Nuclear Security Administration (NNSA) performed a rapid survey of radiation and contamination on March 17-19, 2011 using the Aerial Measuring System. These data were used for the initial NNSA March 22, 2011, report and are available for independent analysis [9]. Additionally, the Ministry of Education, Culture, Sports, Science and Technology, Japan (MEXT), conducted a contamination study using a 2-km mesh from June to August 2011 [10]. This study started 3 months after the main deposition on March 15, 2011. The radionuclides with short half-lives already decayed away; however, ${ }^{134} \mathrm{Cs}$ and ${ }^{137} \mathrm{Cs}$ remained over a wide area around FNPP.

Studies of the biological effect of radiation following the FNPP accident were initiated by Tohoku University as a part of a Comprehensive Dose Evaluation Project Concerning Animals Affected by The Fukushima Daiichi Nuclear Power Plant Accident and a Nuclear Energy Science and Technology and Human Resource Development Project by MEXT using Japanese macaques (Macaca fuscata) sampled in the Fukushima area. Macaques, like humans, belong to the order, Primates. Therefore, the biological effect on macaques might provide important information that can be applied to humans. To estimate exposure, the International Commission of Radiological Protection (ICRP) summarized conversion factors for reference animals under internal exposure to uniformly distributed radionuclides and external exposure to contaminated ground with bodies simulated as ellipsoids in ICRP Publication 108 [11]. The factors are available for 75 radionuclides from ICRP Publication 108. However, the Japanese macaque is not one of the ICRP reference animals. Therefore, we estimated the appropriate conversion factors for the species using the Monte Carlo technique. 


\subsection{Materials and Methods}

\subsection{1 ${ }^{137}$ Cs Contamination Map}

NNSA [9] and MEXT data [10] for ${ }^{137} \mathrm{Cs}$ contamination were combined and interpolated by the Universal Kriging method using System for Automated Geoscientific Analyses-Geographic Information System (SAGA-GIS) software [12]. A variogram was generated, which describes the variance of the difference between ${ }^{137} \mathrm{Cs}$ concentrations at two locations fitted by a quartic function, using SAGA-GIS [10]. The reproducibility of the variogram was $95 \%$ within $70 \mathrm{~km}$ from FNPP. The interpolated values were stored in $1,814 \times 1,854$ meshes for latitudes from 36.51611 to 38.32911 and longitudes from 139.30506 to 141.15896 . The interpolated map is shown in Fig. 14.1. Using this map, ${ }^{137} \mathrm{Cs}$ contamination at the coordinates where macaques were sampled can be calculated.

\subsubsection{Ellipsoid Model}

In ICRP Publication 108, the reference animals in terrestrial conditions are modeled as various ellipsoids [11], as listed in Table 14.1. Therefore, Japanese macaques were also modeled as ellipsoids with a density of $1 \mathrm{~g} / \mathrm{cm}^{3}$ according to ICRP Publication 108 assumption. Japanese macaques were categorized into three groups
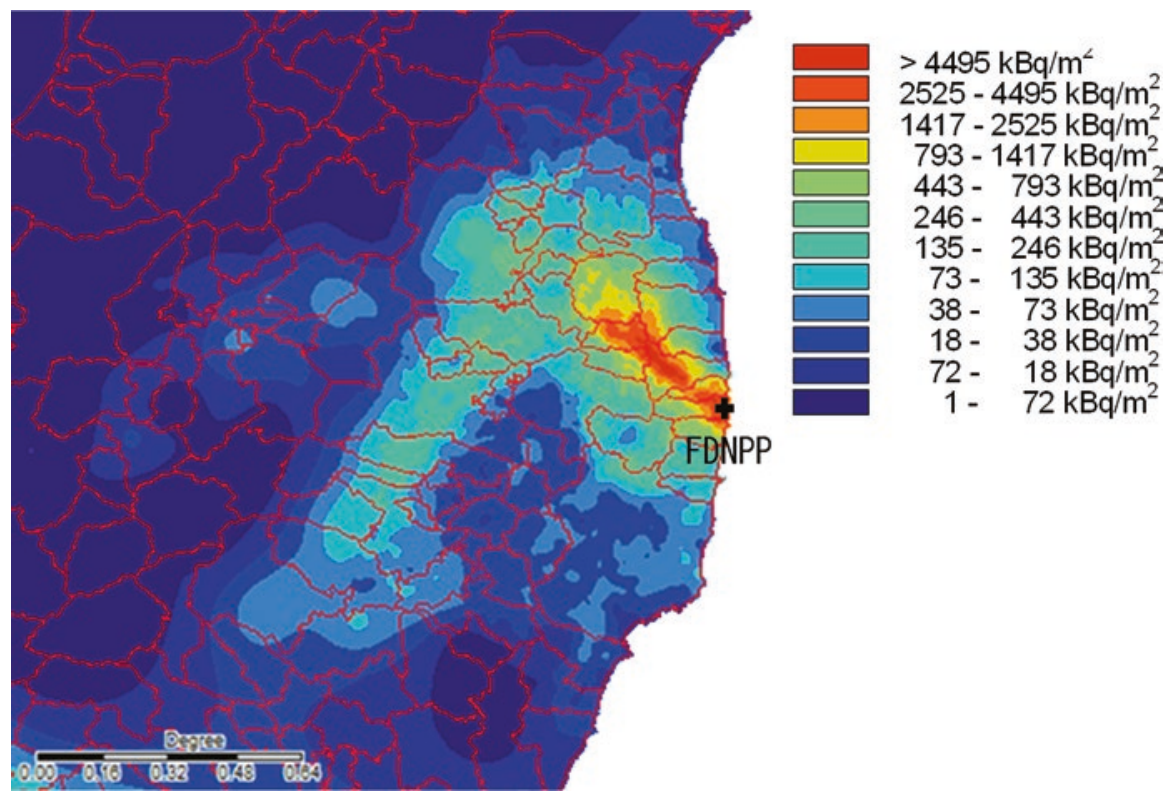

Fig. 14.1 Kriging interpolated map for the combined NNSA and MEXT data 
Table 14.1 Body parameters for the reference animals in ICRP Publication 108 [11] and the calculated effective radius

\begin{tabular}{l|l|l|l}
\hline Reference animal & Body mass $(\mathrm{kg})$ & Body shape proportions (ellipsoid) & Effective radius $(\mathrm{cm})$ \\
\hline Deer & 245 & $1 \times 0.4620 \times 0.4620$ & 38.7 \\
\hline Rat & 0.314 & $1 \times 0.3000 \times 0.2500$ & 4.21 \\
\hline Duck egg & $5.03 \times 10^{-2}$ & $1 \times 0.6670 \times 0.6670$ & 2.29 \\
\hline Duck & 1.26 & $1 \times 0.3330 \times 0.2670$ & 6.69 \\
\hline Frog egg & $5.24 \times 10^{-4}$ & $1 \times 1 \times 1$ & 0.500 \\
\hline Frog & 0.0314 & $1 \times 0.375 \times 0.313$ & 1.96 \\
\hline Bee colony & 28.3 & $1 \times 0.500 \times 0.500$ & 18.8 \\
\hline Bee & $5.89 \times 10^{-4}$ & $1 \times 0.375 \times 0.375$ & 0.520 \\
\hline Earthworm & $5.24 \times 10^{-3}$ & $1 \times 0.100 \times 0.100$ & 1.08 \\
\hline
\end{tabular}

Table 14.2 Japanese macaque models for the walk and sit postures based on physical measurements

\begin{tabular}{|c|c|c|c|c|c|c|}
\hline \multirow[b]{2}{*}{ Axis $(\mathrm{cm})$} & \multicolumn{3}{|c|}{ Walk model } & \multicolumn{3}{|l|}{ Sit model } \\
\hline & $<5 \mathrm{~kg}(\mathrm{~S})$ & $5-10 \mathrm{~kg}(\mathrm{M})$ & $>10 \mathrm{~kg}(\mathrm{~L})$ & $<5 \mathrm{~kg}(\mathrm{~S})$ & $5-10 \mathrm{~kg}(\mathrm{M})$ & $>10 \mathrm{~kg}(\mathrm{~L})$ \\
\hline Major & 15 & 25 & 30 & 15 & 25 & 30 \\
\hline First minor & 6.2 & 9.7 & 12 & 6.2 & 9.7 & 12 \\
\hline Second minor & 4.1 & 6.4 & 8 & 4.1 & 6.4 & 8 \\
\hline Height & 20 & 30 & 40 & - & - & - \\
\hline
\end{tabular}

according to the body size, namely, small (S), middle (M) and large (L), with the weight of less than $5 \mathrm{~kg}, 5-10 \mathrm{~kg}$ and greater than $10 \mathrm{~kg}$, corresponding to the sampled macaques. The ellipsoid dimensions were based on the physical measurements of 52 macaques obtained by Tohoku University and the values are listed in Table 14.2. Two types of postures, the walk and sit postures, were considered and are also listed in Table 14.2.

\subsubsection{Conversion Factor Calculation}

The conversion factors for internal exposure to uniformly distributed radionuclides in an ellipsoid and external exposure to uniformly contaminated ground from 0 to $0.5 \mathrm{~cm}$ were calculated using PHITS code [13]. The calculation geometry of air occupying a $10 \times 10 \times 10 \mathrm{~m}$ area and 50-cm-deep ground soil was taken into account. The ellipsoid macaque was set at the center of the ground surface. To minimize calculation time, the four side boundaries were set to a mirror condition. Gamma-rays and $\beta$-particles were separately calculated for seven radionuclides, namely, ${ }^{129} \mathrm{Te},{ }^{129 \mathrm{~m}} \mathrm{Te},{ }^{131} \mathrm{I},{ }^{132} \mathrm{Te},{ }^{132} \mathrm{I},{ }^{134} \mathrm{Cs}$ and ${ }^{137} \mathrm{Cs}$. The $\gamma$-ray energies and emission rates for the radionuclides were obtained from the National Nuclear Data Center [14]. Beta-particle energy spectra were obtained from the literature [15, 16], and the internal conversion electrons for each radionuclide were obtained from the website of the National Nuclear Data Center [14]. The energy deposition in the ellipsoids was calculated for each $\gamma$-ray and each electron source. In addition, to consider the 
Fig. 14.2 Calculation geometry for PHITS

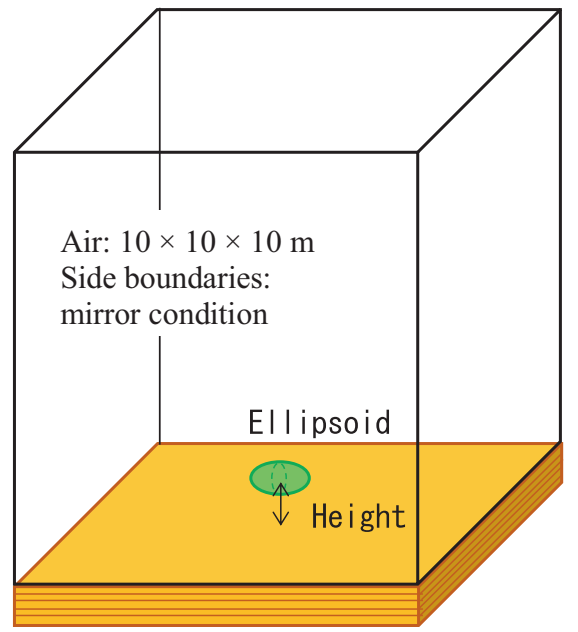

Soil layer: 0-0.5 cm, 0.5-1 cm, 1-2 cm, 2-5 $\mathrm{cm}, 5-10 \mathrm{~cm}, 10-15 \mathrm{~cm}$, and $15-20 \mathrm{~cm}$.

depth profile of radionuclides, the deposition energy in the walk model for body size L was also calculated for sources uniformly distributed in six soil layers, namely, $0.5-1 \mathrm{~cm}, 1-2 \mathrm{~cm}, 2-5 \mathrm{~cm}, 5-10 \mathrm{~cm}, 10-15 \mathrm{~cm}$ and 15-20 cm (Fig. 14.2).

The external exposure conversion factors were derived by weighing each deposition energy for the depth profile of the radionuclide. The factor $D_{i}^{\mathrm{ex}}$ ((mGy/day)/ $\left(\mathrm{Bq} / \mathrm{m}^{2}\right)$ ) of the $i$ th radionuclide from depth layer $d_{k}$ is expressed by

$$
D_{i}^{e x}\left(d_{k}\right)=\sum_{j=\gamma, \beta} \frac{E_{i j}\left(d_{k}\right)}{m} I_{J} S \cdot 3600 \cdot 24 \cdot 1000,
$$

where subscript $j$ indicates emitted $\gamma$-rays or $\beta$-particles, $I_{j}$ is the emission rate for emitted $\gamma$-rays or $\beta$-particles, $m$ is the mass of the macaque-simulating ellipsoid, $E$ is the deposition energy in the ellipsoid by emitted $\gamma$-rays and $\beta$-particles and $S$ is the calculated area expressed in $\mathrm{m}^{2}$. In the case of soil surface contamination, similar to the ICRP Publication 108 assumption, the depth layer $d_{l}$ is only $0-0.5 \mathrm{~cm}$. To estimate the factor for the depth profile of radionuclides, the fraction of radionuclides as a function of depth, $f\left(d_{k}\right)$, is introduced and summed for seven layers:

$$
D_{i}^{e x}=\sum_{7}^{k=1} f_{1}\left(d_{k}\right) \cdot D_{i}^{e x}\left(d_{k}\right)
$$

The internal exposure conversion factor $D_{i}^{\mathrm{in}}((\mathrm{mGy} / \mathrm{d}) /(\mathrm{Bq} / \mathrm{kg}))$ for each radionuclide $i$ was calculated using each deposition energy as follows:

$$
D_{i}^{i n}=\sum_{j=\gamma, \beta} \frac{E_{i j}}{m} I_{j} m \cdot 3600 \cdot 24 \cdot 1000 .
$$


Fig. 14.3 Tested depth profiles. Type 1, farmland; Type 2, normal land

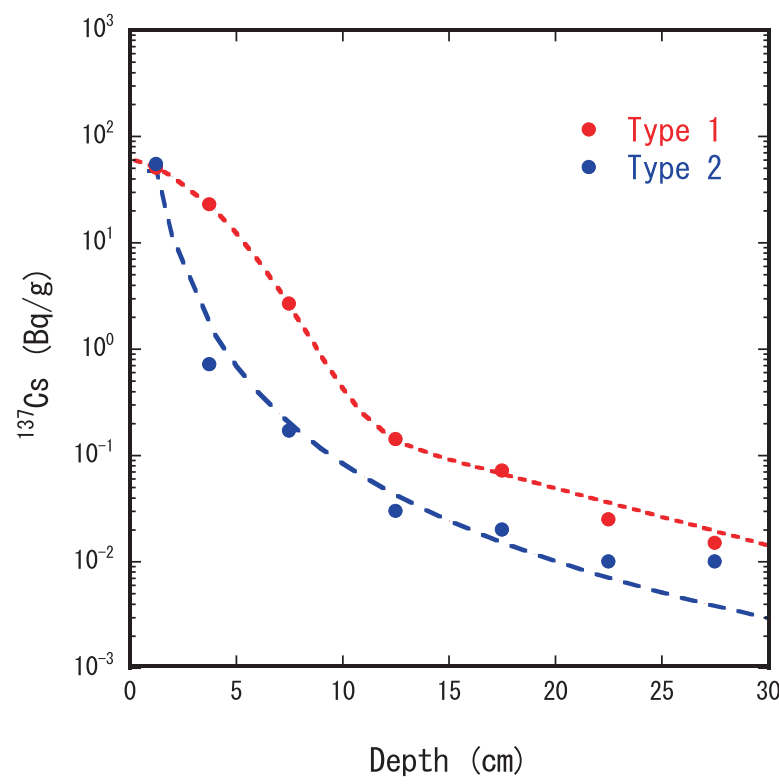

\subsubsection{Depth Profile}

There is a lack of depth profile data, except for radioactive Cs. The depth profiles of ${ }^{137} \mathrm{Cs}$ radioactivity have been measured at various locations [17-20]. The relaxation mass depths of ${ }^{137} \mathrm{Cs}$ have been reported as time-dependent values of $1.1-1.5 \mathrm{~g} / \mathrm{cm}^{2}$ for the period from December 2012 to December 2013 [17]; $0.9 \mathrm{~g} / \mathrm{cm}^{2}$ for soil with a low clay content [18]; $1.56 \mathrm{~g} / \mathrm{cm}^{2}$, on average, for paddy soil [19]; and 1.04, 1.38, 1.05 and $1.29 \mathrm{~g} / \mathrm{cm}^{2}$ in April 2011, October 2011, December 2011 and March 2012, respectively [20]. The conversion factor for the ${ }^{137} \mathrm{Cs}$ depth-profiled soil was calculated using the relaxation mass depths from 0.5 to 2.7 according to Eq. (14.2). Additionally, the typical depth profiles for our measurement, as shown in Fig. 14.3, were tested.

\subsection{Results and Discussion}

\subsubsection{Conversion Factor}

The calculated conversion factors for the surface layer for seven radionuclides are listed in Table 14.3. The external exposure results for the walk model and the internal exposure results were compared with those in ICRP Publication 108 against the effective radius and are shown in Fig. 14.4. The calculated factor and those of ICRP Publication 108 agree within 20\%. Therefore, if we allow for $20 \%$ uncertainty, the conversion factor in ICRP Publication 108 for the effective radius can be used. 
14 Dose Estimation of External and Internal Exposure in Japanese Macaques After...

Table 14.3 Estimated conversion factors for the external exposure rates of the walk and sit model for surface contamination and the internal exposure rate

\begin{tabular}{|c|c|c|c|c|}
\hline \multirow[b]{2}{*}{ Radionuclide } & \multirow[b]{2}{*}{$\begin{array}{l}\text { Body } \\
\text { group }\end{array}$} & \multicolumn{2}{|c|}{ Conversion factor $\left[(\mathrm{mGy} / \mathrm{d}) /\left(\mathrm{Bq} / \mathrm{m}^{2}\right)\right]$} & \multirow{2}{*}{$\begin{array}{l}\text { Conversion factor } \\
{[(\mathrm{mGy} / \mathrm{d}) /(\mathrm{Bq} / \mathrm{kg})]} \\
\text { Internal }\end{array}$} \\
\hline & & $\begin{array}{l}\text { External, walk } \\
\text { model }\end{array}$ & External, sit model & \\
\hline \multirow[t]{3}{*}{${ }^{134} \mathrm{Cs}$} & $\mathrm{L}$ & $9.50 \times 10^{-5}$ & $1.00 \times 10^{-4}$ & $7.63 \times 10^{-3}$ \\
\hline & $\mathrm{M}$ & $1.02 \times 10^{-4}$ & $1.07 \times 10^{-4}$ & $6.72 \times 10^{-3}$ \\
\hline & $\mathrm{S}$ & $1.17 \times 10^{-4}$ & $1.16 \times 10^{-4}$ & $5.14 \times 10^{-3}$ \\
\hline \multirow[t]{3}{*}{${ }^{137} \mathrm{Cs}$} & $\mathrm{L}$ & $3.53 \times 10^{-5}$ & $3.77 \times 10^{-5}$ & $4.91 \times 10^{-3}$ \\
\hline & M & $3.81 \times 10^{-5}$ & $3.93 \times 10^{-5}$ & $4.58 \times 10^{-3}$ \\
\hline & $\mathrm{S}$ & $4.32 \times 10^{-5}$ & $4.31 \times 10^{-5}$ & $4.01 \times 10^{-3}$ \\
\hline \multirow[t]{3}{*}{${ }^{132} \mathrm{I}$} & $\mathrm{L}$ & $1.17 \times 10^{-4}$ & $1.22 \times 10^{-4}$ & $9.87 \times 10^{-3}$ \\
\hline & M & $1.24 \times 10^{-4}$ & $1.33 \times 10^{-4}$ & $9.27 \times 10^{-3}$ \\
\hline & $\mathrm{S}$ & $1.46 \times 10^{-4}$ & $1.44 \times 10^{-4}$ & $8.25 \times 10^{-3}$ \\
\hline \multirow[t]{3}{*}{${ }^{131} \mathrm{I}$} & $\mathrm{L}$ & $2.23 \times 10^{-5}$ & $2.21 \times 10^{-5}$ & $5.02 \times 10^{-3}$ \\
\hline & M & $2.40 \times 10^{-5}$ & $2.35 \times 10^{-5}$ & $4.60 \times 10^{-3}$ \\
\hline & $\mathrm{S}$ & $2.75 \times 10^{-5}$ & $2.60 \times 10^{-5}$ & $3.88 \times 10^{-3}$ \\
\hline \multirow[t]{3}{*}{${ }^{132} \mathrm{Te}$} & $\mathrm{L}$ & $1.18 \times 10^{-5}$ & $9.95 \times 10^{-6}$ & $3.57 \times 10^{-3}$ \\
\hline & M & $1.29 \times 10^{-5}$ & $1.08 \times 10^{-5}$ & $3.15 \times 10^{-3}$ \\
\hline & $\mathrm{S}$ & $1.45 \times 10^{-5}$ & $1.18 \times 10^{-5}$ & $2.43 \times 10^{-3}$ \\
\hline \multirow[t]{3}{*}{${ }^{129 m} \mathrm{Te}$} & $\mathrm{L}$ & $3.26 \times 10^{-6}$ & $3.09 \times 10^{-6}$ & $7.86 \times 10^{-3}$ \\
\hline & M & $4.20 \times 10^{-6}$ & $3.68 \times 10^{-6}$ & $7.83 \times 10^{-3}$ \\
\hline & $\mathrm{S}$ & $5.81 \times 10^{-6}$ & $5.20 \times 10^{-6}$ & $7.77 \times 10^{-3}$ \\
\hline \multirow[t]{3}{*}{${ }^{129} \mathrm{Te}$} & $\mathrm{L}$ & $6.34 \times 10^{-6}$ & $5.55 \times 10^{-6}$ & $6.48 \times 10^{-3}$ \\
\hline & M & $7.48 \times 10^{-6}$ & $6.50 \times 10^{-6}$ & $6.43 \times 10^{-3}$ \\
\hline & $\mathrm{S}$ & $1.18 \times 10^{-5}$ & $9.58 \times 10^{-6}$ & $6.34 \times 10^{-3}$ \\
\hline
\end{tabular}

(a)

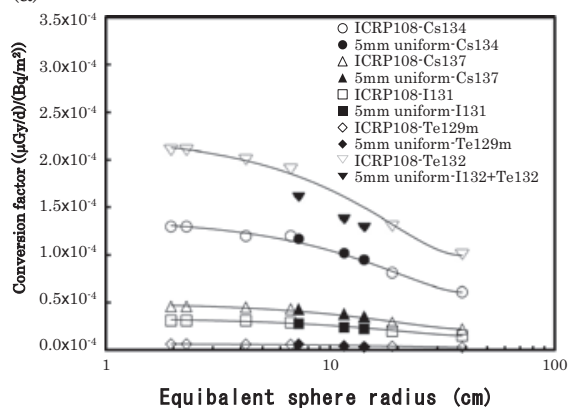

(b)

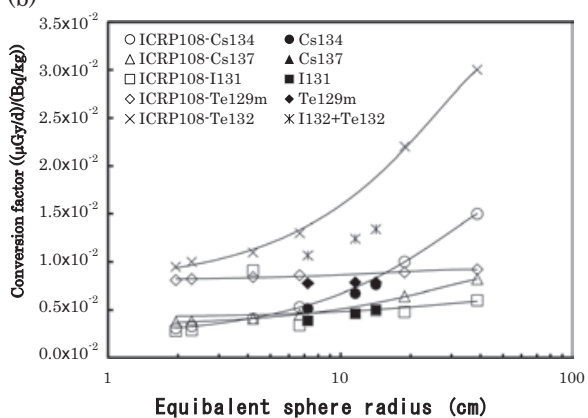

Fig. 14.4 (a) External exposure for the walk model and (b) internal exposure for the Japanese macaque. Values were compared with those in ICRP Publication 108 against the effective radius 
Fig. 14.5 Conversion factor ratio of the walk-to-sit model as a function of $\bar{E}$

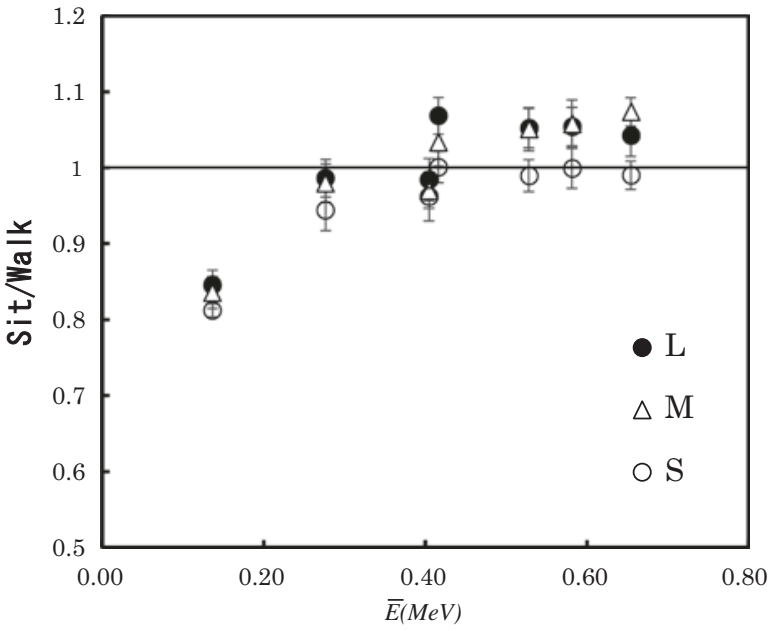

The conversion factor ratio of external exposure for the walk to the sit model is plotted as a function of $\bar{E}$, which is defined as the sum of mean $\gamma$-ray and $\beta$-particle energies, in Fig. 14.5. The ratio is consistent with unity within statistical uncertainty, except for the lowest $\bar{E}$ of ${ }^{132} \mathrm{Te}$. The ratio for ${ }^{132} \mathrm{Te}$, which emits low-energy $\gamma$-rays and $\beta$-particles, is approximately 0.83 . This is due to the shielding effect by an individual's own body. Therefore, except for low-energy $\beta$-particles and $\gamma$-rays, the conversion factors for both the walk model and sit model are approximately equal.

\subsubsection{Conversion Factor for Depth-Profiled Radionuclides}

The conversion factors for the seven depth-profiled radionuclides with a relaxation depth from 0.6 to 2.6 and measured depth profiles of ${ }^{134} \mathrm{Cs}$ and ${ }^{137} \mathrm{Cs}$ in Iitate Village, Fukushima Prefecture, in comparison with the $0-0.5 \mathrm{~cm}$ uniform factor are shown in Fig. 14.6a, b, respectively. The relaxation depths of ${ }^{137} \mathrm{Cs}$ radioactivity from previous studies [17-20] are shown in light red and ranged from 0.9 to $1.5 \mathrm{~g} / \mathrm{cm}^{2}$. A soil self-shielding factor introduced as a ratio of the conversion factor for the depth profiles to that for the uniformly distributed factor in surface soil characterized by the relaxation depth is summarized in Table 14.4. The soil self-shielding factors for ${ }^{134} \mathrm{Cs}$ and ${ }^{137} \mathrm{Cs}$ were 0.74 and 0.71 , respectively. The shielding factor for Type 1 for the slowest measured depth profiles for farmland in Fig. 14.6b was less than that for a relaxation depth of $2.6 \mathrm{~g} / \mathrm{cm}^{2}$. However, the shielding factor for Type 2 for the typical depth profile for undisturbed land is consistent with those for the relaxation depth of $0.9-1.5 \mathrm{~g} / \mathrm{cm}^{2}$. The variation within the range of $0.9-1.5 \mathrm{~g} / \mathrm{cm}^{2}$ corresponds to the variation in the conversion factor for ${ }^{134} \mathrm{Cs}$ or ${ }^{137} \mathrm{Cs}$, which was less than $8 \%$. 


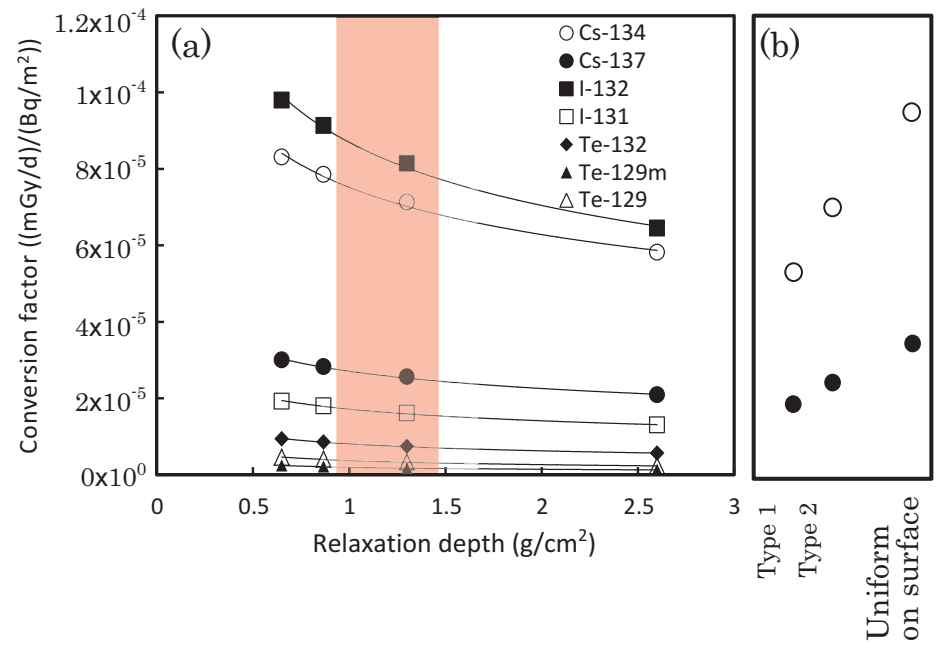

Fig. 14.6 (a) Calculated conversion factors of walk model for seven radionuclides of relaxation depth and (b) typical measured depth profiles

Table 14.4 Soil selfshielding factor for seven radionuclides

\begin{tabular}{l|l}
\hline Radionuclide & Soil shielding factor \\
\hline${ }^{134} \mathrm{Cs}$ & 0.74 \\
\hline${ }^{137} \mathrm{Cs}$ & 0.71 \\
\hline${ }^{132} \mathrm{I}$ & 0.68 \\
\hline${ }^{131} \mathrm{I}$ & 0.71 \\
\hline${ }^{132} \mathrm{Te}$ & 0.62 \\
\hline${ }^{129 \mathrm{~m}} \mathrm{Te}$ & 0.54 \\
\hline${ }^{129} \mathrm{Te}$ & 0.52 \\
\hline
\end{tabular}

\subsubsection{Example of External Exposure Estimation}

To consider cumulative exposure to soil contamination, temporal changes in the air dose from radionuclides deposited on the ground are good references. The air dose rate from seven radionuclides from radioactivity concentrations was estimated around FNPP in 2011 [9, 10]. The air dose rate changes were estimated for several locations. For example, the estimated dose rate change in Iitate Village assuming only the physical half-life [2] is shown in Fig. 14.7. Integrating over time, the cumulative air dose can be estimated. The cumulative air dose normalized by the dose at 200 years after deposition and the radionuclide contribution as a function of time are shown in Fig. 14.8a, b, respectively. The sum of the ${ }^{134} \mathrm{Cs}$ and ${ }^{137} \mathrm{Cs}$ contributions to the cumulative air dose at 1 year after deposition or later exceeds $90 \%$. In the sampled macaques, exposure is expected to be the same as the contributions to the air dose. Accordingly, the external exposure for some samples after 1 year following the FNPP accident can be estimated by only radioactive ${ }^{134} \mathrm{Cs}$ and ${ }^{137} \mathrm{Cs}$, neglecting the $10 \%$ contribution of external exposure to other radionuclides. 
Fig. 14.7 Estimated dose rate change in Iitate Village assuming only the physical half-life

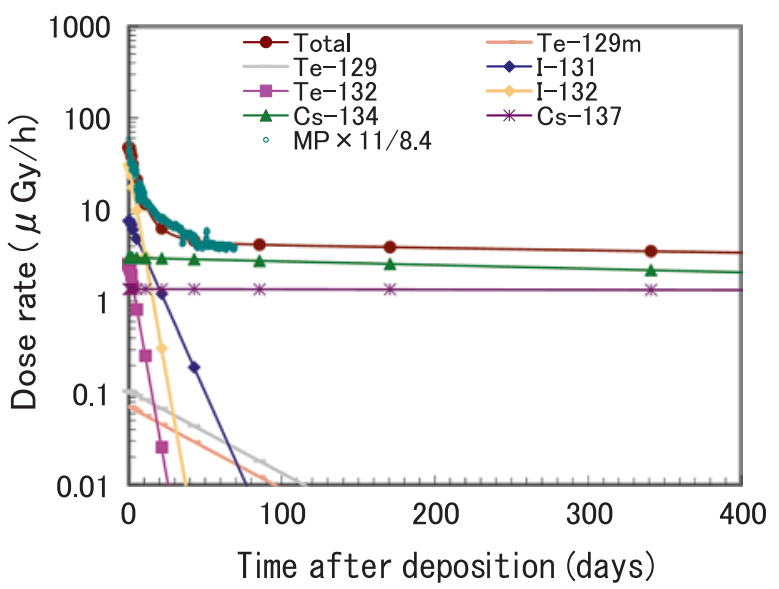

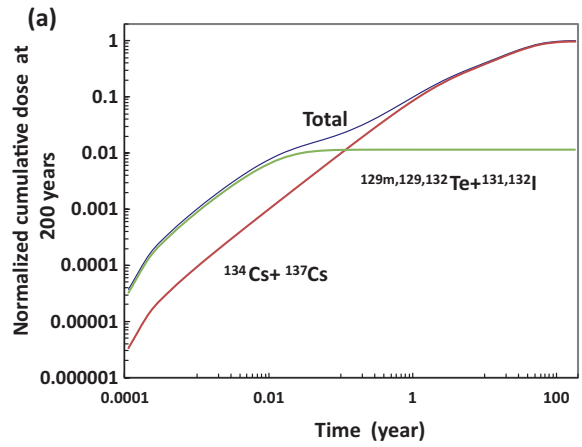

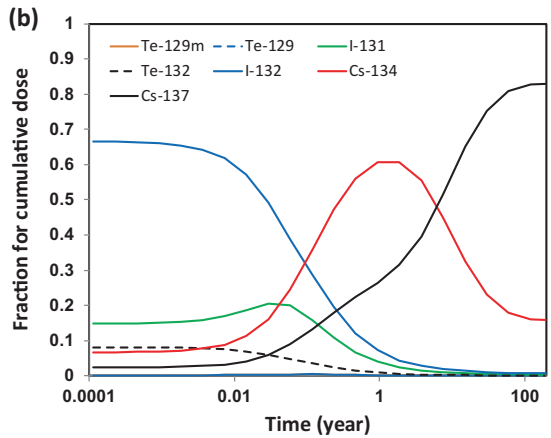

Fig. 14.8 (a) Cumulative dose in Japanese macaques against time since deposition normalized by the dose at 200 years; (b) radionuclide contribution as a function of time

Using the ${ }^{134} \mathrm{Cs}$ and ${ }^{137} \mathrm{Cs}$ conversion factors for the walk model, the external, the internal and the total exposures were calculated for the sampled macaques at Namie Town, Fukushima Prefecture, in 2013. Only ${ }^{137} \mathrm{Cs}$ concentration and ${ }^{134} \mathrm{Cs}$ concentration, which is the same as ${ }^{137} \mathrm{Cs}$ concentration in March 2011, were used in this estimation. The ground concentration of ${ }^{137} \mathrm{Cs}$ (interpolated values in Fig. 14.1) and the ${ }^{137} \mathrm{Cs}$ concentration in macaque bodies measured at Tohoku University [21] were used in this calculation. To account for the effect of the depth profile, the soil selfshielding factor of the depth profile for a relaxation depth of $1.3 \mathrm{~g} / \mathrm{cm}^{2}$ was assumed to be 0.74 for ${ }^{134} \mathrm{Cs}$ and 0.71 for ${ }^{137} \mathrm{Cs}$. The macaques were caught in 2013 or later; therefore, only exposure to ${ }^{134} \mathrm{Cs}$ and ${ }^{137} \mathrm{Cs}$ was taken into account. Additionally, the ratio of the accumulated concentration of ${ }^{134} \mathrm{Cs}$ to ${ }^{137} \mathrm{Cs}$ was assumed to be unity. The estimated total exposures ranged from 0.26 to $1.6 \mathrm{~Gy}$, as shown in Table 14.5. Two sampled macaques showed the body weight less than $2 \mathrm{~kg}$. There is a possibility that these 2 macaques were born after the FNPP accident. The average exposure was $0.64 \mathrm{~Gy}$ in averaged over the 11 sampled macaques except for the 2 macaques. 


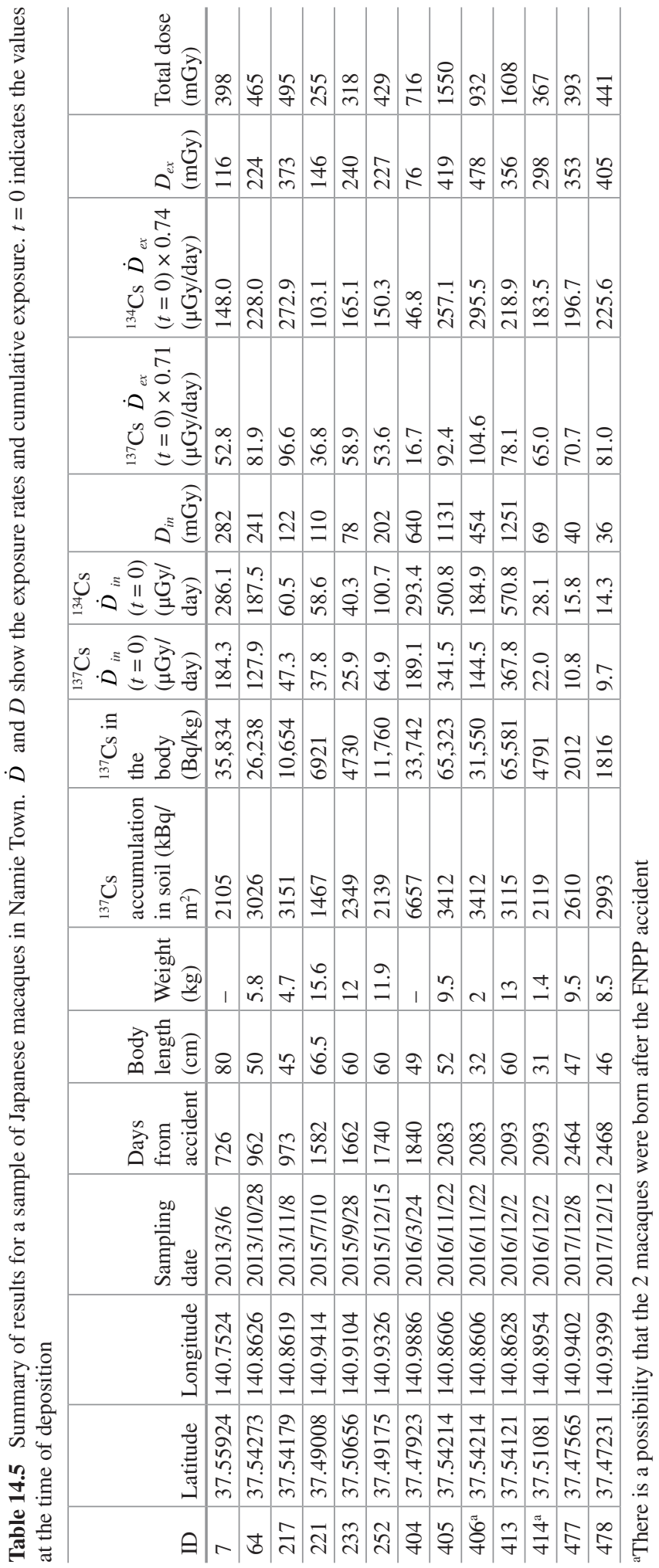




\subsection{Conclusions}

The cumulative external and internal exposures attributed to the FNPP accident were estimated for Japanese macaques around FNPP. Conversion factors for Japanese macaques, modeled as ellipsoids, for external exposure from contaminated ground and internal exposure uniformly distributed in the body were calculated. The estimated conversion factors for seven radionuclides, namely, ${ }^{129} \mathrm{Te}$, ${ }^{129 m} \mathrm{Te},{ }^{131} \mathrm{I},{ }^{132} \mathrm{Te},{ }^{132} \mathrm{I},{ }^{134} \mathrm{Cs}$ and ${ }^{137} \mathrm{Cs}$, agreed within $20 \%$ with those in ICRP Publication 108 using an effective radius.

The conversion factors for depth-profiled ${ }^{134} \mathrm{Cs}$ and ${ }^{137} \mathrm{Cs}$ characterized by the relaxation depth were also estimated. The conversion factors are expressed by the factor for a uniform distribution at the $0-0.5 \mathrm{~cm}$ surface multiplied by a soil selfshielding factor of 0.74 for ${ }^{134} \mathrm{Cs}$ and 0.71 for ${ }^{137} \mathrm{Cs}$ and with a relaxation depth of $1.3 \mathrm{~g} / \mathrm{cm}^{2}$.

The external, the internal and the total exposures for 13 sampled macaques were estimated using the calculated conversion factors. The estimated cumulative exposures for the periods from the accident occurred to the sampling date, ranged from 0.26 to $1.6 \mathrm{~Gy}$. The average exposure was $0.64 \mathrm{~Gy}$ in averaged over the 11 sampled macaques except for the 2 macaques which might be born after the FNPP accident.

Acknowledgments The authors are grateful to Prof. Chary Rangacharyulu, the University of Saskatchewan, for his advice. The radioactivity measurements were performed at the radiation facility of the Graduate School of Engineering, Hiroshima University, and at the Department of Chemistry, Faculty of Science, and Graduate School of Science, Tohoku University. The authors are grateful to Ms. Aya Kado at the radiation facility of Hiroshima University and Mr. Hiroaki Tamaki, Mr. Takumi Ono and Mr. Kazuma Koarai of Tohoku University. This work is supported by the Nuclear Energy Science and Technology and Human Resource Development Project (Through Concentrating Wisdom) (281302) from the Ministry of Education, Culture, Sports, Science and Technology of Japan.

\section{References}

1. Endo S, Kimura S, Takatsuji T et al (2012) Measurement of soil contamination by radionuclides due to Fukushima Daiichi Nuclear Power Plant accident and associated cumulative external dose estimation. J Environ Radioact 111:18-27

2. Imanaka T, Endo S, Sugai M et al (2012) Early radiation survey of the Iitate Village heavily contaminated by the Fukushima Daiichi accident, conducted on 28 and 29 March 2011. Health Phys 102:680-686

3. Fukuda T, Kino Y, Abe Y et al (2013) Distribution of artificial radionuclides in abandoned cattle in the evacuation zone of the Fukushima Daiichi nuclear power plant. PLoS One 8:e54312

4. Ochiai K, Hayama S, Nakiri S et al (2014) Low blood cell counts in wild Japanese monkeys after the Fukushima Daiichi nuclear disaster. Sci Rep 4:5793

5. Takahashi S, Inoue K, Suzuki M et al (2015) A comprehensive dose evaluation project concerning animals affected by the Fukushima Daiichi Nuclear Power Plant accident: its set-up and progress. J Radiat Res 56(S1):i36-i41

6. Hiyama A, Nohara C, Kinjo S et al (2012) The biological impacts of the Fukushima nuclear accident on the pale grass blue butterfly. Sci Rep 2:270 
7. Akimoto S (2014) Morphological abnormalities in gall-forming aphids in a radiationcontaminated area near Fukushima Daiichi: selective impact of fallout? Ecol Evol. https://doi. org/10.1002/ece3.949

8. Hayama S, Nakiri S, Nakanish S et al (2013) Concentration of radiocesium in the wild Japanese monkey (Macaca fuscata) over the first 15 months after the Fukushima Daiichi nuclear disaster. PLoS One 8:e68530

9. Musolino SV, Clark H, McCullough T et al (2012) Environmental measurements in an emergency: this is not a drill. Health Phys 102(5):516-526

10. Minister of Education, Culture, Sports, Science and Technology (MEXT) (2011) Map of radiocesium in soil. http://www.mext.go.jp/b_menu/shingi/chousa/gijyutu/017/shiryo/_icsFiles/ afieldfile/2011/09/02/1310688_2.pdf. Last accessed 29 Aug 2011

11. International Commission on Radiological Protection (ICRP) (2008) Environmental protection: the concept and use of reference animals and plants, Ann. ICRP 38 (4-6), ICRP publication 108

12. Cimmery V SAGA user guide, updated for SAGA version 2.0.5, 2007-2010. http://www.sagagis.org/en/index.html. Last accessed 8 July 2018

13. Sato T, Niita K, Matsuda N et al (2013) Particle and heavy ion transport code system PHITS, version 2.52. J Nucl Sci Technol 50:913-923

14. National Nuclear Data Center (NNDC). NNDC data base: interactive chart of nuclides. http:// www.nndc.bnl.gov/chart/. Last update: 1 February 2017. Last accessed 12 Feb 2017

15. Endo S, Tanaka K, Kajimoto T et al (2014) Estimation of $\beta$-ray dose in air and soil from Fukushima Daiichi Power Plant accident. J Radiat Res 55:476-483

16. Endo S, Kajimoto T, Tanaka $\mathrm{K}$ et al (2015) Mapping of cumulative $\beta$-ray dose on the ground surface surrounding the Fukushima area. J Radiat Res 56:i48-i55

17. Matsuda N, Mikami S, Shimoura S et al (2015) Depth profiles of radioactive cesium in soil using a scraper plate over a wide area surrounding the Fukushima Dai-ichi Nuclear Power Plant, Japan. J Environ Radioact 139:427-434

18. Kato H, Onda Y, Teramage M (2012) Depth distribution of ${ }^{137} \mathrm{Cs},{ }^{134} \mathrm{Cs}$, and ${ }^{131} \mathrm{I}$ in soil profile after Fukushima Dai-ichi Nuclear Power Plant accident. J Environ Radioact 111:59-64

19. Shiozawa S, Tanoi K, Nemoto K et al (2011) Vertical concentration profiles of radioactive caesium and convective velocity in soil in a paddy field in Fukushima. Radioisotopes 60(8):323-328

20. Honda M, Matsuzaki H, Miyake Y et al (2015) Depth profile and mobility of ${ }^{129} \mathrm{I}$ and ${ }^{137} \mathrm{Cs}$ in soil originating from the Fukushima Dai-ichi Nuclear Power Plant accident. J Environ Radioact 146:35-43

21. Suzuki M. (2015) Compiled data of Japanese monkeys sampled in Fukushima Area by A comprehensive dose evaluation project concerning animals affected by the Fukushima Daiichi Nuclear Power Plant accident, Personal communications

Open Access This chapter is licensed under the terms of the Creative Commons Attribution 4.0 International License (http://creativecommons.org/licenses/by/4.0/), which permits use, sharing, adaptation, distribution and reproduction in any medium or format, as long as you give appropriate credit to the original author(s) and the source, provide a link to the Creative Commons license and indicate if changes were made.

The images or other third party material in this chapter are included in the chapter's Creative Commons license, unless indicated otherwise in a credit line to the material. If material is not included in the chapter's Creative Commons license and your intended use is not permitted by statutory regulation or exceeds the permitted use, you will need to obtain permission directly from the copyright holder.

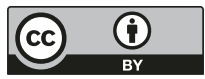

